\title{
Evaluation of Lime-Cement-Fly Ash Stabilization in Curtailing the Dispersive Potential of Australian Sodic Soil
}

\author{
Raghavendra Vasudeva Upadhyaya*, Jerome Akpoge Egwurube, Prince Bhandari, Prasad Gudimetla \\ and Angela Rengifo
}

Central Queensland University, R3.23/120 Spencer street, Melbourne, VIC 3000 Australia

Received 25 March 2021; Accepted 29 June 2021

\begin{abstract}
Sodic soils account for nearly one third of Australia's land mass and pose several challenges such as dispersion and erosion, thus destabilizing vast eco-systems. Chemical stabilizers such as lime, cement, fly ash etc., improve the mechanical performance of such soils and reduce their dispersivity. This study presents the results of a novel triple blend stabilization method for strongly sodic soil with Exchangeable Sodium Percentage (ESP) in 15-25\%. Lime, cement and fly ash (LCF) were adopted in four different blend proportions to achieve at least 1.5MPa Unconfined Compressive Strength (UCS) as per Transport and Main Roads (TMR) specification. The results indicate that B4-4\% with 20/50/30 LCF yielded the best performance with lowest shrinkage of $2.9 \%$ and higher dry density $2126.4 \mathrm{~kg} / \mathrm{m}^{3}$. Regression analysis of UCS results projected that an additional $2.53 \%$ soil-stabilizer replacement is required to improve the performance of B4 from $0.86 \mathrm{MPa}$ to reach 1.5 MPa. Scanning Electron Microscopy (SEM) analysis showed needle-like ettringite crystals and Calcium-SilicateHydrates (CSH) net-like structures over 28-day curing. X-Ray diffractometry (XRD) indicated a drop of $20.8 \%$ in $\mathrm{Na}^{+}$and $20.3 \%$ increase in $\mathrm{Ca}^{++}$. The triple blend stabilization technique enhances UCS performance by $167 \%$ with a less than $5 \%$ of the total volume of the additives when compared to the single and double blends.
\end{abstract}

Keywords: Sodic soil, Dispersive, Mellowing, Triple blend, Ettringite, stabilization

\section{Introduction}

Sodic soils are widely found in various parts of the world, especially Australia bearing the highest land formation of about 339,971 thousand hectares comprising of $38.4 \%$ of the total landmass [1] and its stabilization presents a major challenge for environmental management as well as infrastructural development [2]. Dispersiveness of sodic soil is mainly due to the presence of exchangeable sodium ions on clay surfaces which weakens the bonding between soil particles when exposed to moisture thus leading to soilstructure collapse and erosion [3]. A simple way to prevent these problems is to replace dispersive soils with an engineered soil but in many cases, chemical treatment has been preferred so that dispersive soils can be reused [4]. Geotechnical engineers have been adopting chemical blend proportions with cement, lime, gypsum, silica fume, Ground Granulated Blast Furnace Slag (GGBFS) and fly ash for upgrading the strength characteristics of subgrade material which proves to be economical and equally effective than replacing the unstable soil [5-10].

The most common practice has been the use of single blend stabilizer (lime, cement or fly ash) out of which the profuse application of cement has resulted to early strength gain but higher susceptibility to shrinkage cracks [12,15-16]. Later advancements investigated the efficacy in double stabilization where cement or lime were used in conjunction with fly ash or slag which drastically reduced the dispersive potential of sodic soil under half-curing periods with

*E-mail address: r.vasudevaupadhyaya@cqu.edu.au ISSN: 1791-2377 @ 2021 School of Science, IHU. All rights reserved. doi:10.25103/jestr.143.19 significant increase in UCS and CBR values [6-7,16]. The incorporation of the triple blend for sodic soil stabilization is an emerging concept to evaluate the physico-chemical and mechanical performance of dispersive soil. This technique involves treating sub-grade or sub-base layer with medium plasticity index (between $10 \%$ to $20 \%$ ) where lime, cement and fly ash (LCF) blends tend to positively reflect on increasing the plasticity index, permeability and shrink-swell characteristics [15-18]. Literature evidence suggest that very limited research has been undertaken to explore the potential of triple blend stabilization and its accelerated curing periods. One example is the Department of Transport and Main Roads (TMR) in Queensland, Australia adopting this methodology in their rehabilitation of fatigued pavement Project in 2014 [17]. Queensland's TMR specification [18] recommends the use of triple blend stabilizers (L-30\%, C-40\% and F-30\%) for soils LS $\leq 6 \%$, whereas a combination of (L- $40 \%, \mathrm{C}-30 \%$, and F-30\%) stabilizers for other cases targeting an unconfined compressive strength of 1.5MPa at 28-days. Likewise, Bullen and Suciu [15] compared the strength of two triple blends in different combinations of Portland cement, Ground Granulated Blast-Furnace Slag (GGBFS) and fly ash where the blend with higher content of fly ash was observed to be most economic and reliable in terms of strength attainment. The importance of triple blend stabilization lies in determining the effective mix design that can significantly combine the merits of individual stabilizers such lime, cement and fly ash in improving the overall workability, strength, durability and rheology characteristics. Apart from combined efficacy, the recycling of coal combustion byproducts such as fly ash can lead to cost savings in material and thereby, reduce the global carbon footprint. 
SEM analysis provides us a better understanding on the material-level changes occurring as a result of LCF stabilization on dispersive soils. It is understood that the use of Calcium ion inducing agents such as lime, cement and fly ash helps to replace sodium ions from the soil resulting in better soil structure [19]. At a microscopic level, the composition of lime and water leads to the $\mathrm{pH}$ of the soil to increase above 10.5 which enables clay particles to break down such that Silica and Alumina are released/solubilized to react with calcium from lime to form Calcium-SilicateHydrates $(\mathrm{CSH})$ and Calcium-Aluminum-Hydrates $(\mathrm{CAH})$ which are cementitious products similar to formed in Portland cement [11]. The surface morphology for cement-stabilized dispersive soil with ultra-fine silica fume resulted in a denser surface as the curing period increased whereas the surface without silica fume developed some microcracks when studied at a microstructural level [20]. Likewise, the analysis for fly ash substituted cement mortar was conducted to observe the strength attainment parameters at SEM level and was found that the rate of curing period induced the formation of C-S-H net-like structures which is a time-dependent phenomenon where the mortar strength increased exponentially resulting in strength gain for the samples [21]. This paper therefore aims to determine the optimum percentages of lime, cement and fly ash (LCF) triple blend proportion that would achieve the minimum Unconfined Compressive Strength (UCS) of $1.5 \mathrm{MPa}$ Australian specification. Four different proportions of lime/cement/flyash blends were investigated namely 30/40/30, 25/40/35, 20/40/40 and 20/50/30 for strongly sodic soil.

\section{Materials and Methods}

\subsection{Material properties and initial testing}

A soil with Exchangeable Sodium Percentage (ESP) greater than 6 is generally regarded as being a sodic (i.e Na-affected) soil in Australia. There are three ratings using ESP for soil sodicity namely non-sodic (0-5), sodic (5-15) and strongly sodic $(>15)$. The sample considered in this study were collected from the upper subsoil at Murgheboluc, Australia ($38.0832 \mathrm{~N}, 144.14906$ E). Agriculture Victoria's [22] classification maps classify it as strongly sodic soil. The soil sampled was characterized on the basis of severe corrodibility and moisture susceptibility behaviour. Basic soil tests such as Atterberg's limit [23,24], compaction characteristics [25,26] and dispersivity $[27,28]$, were conducted on the control soil sample and stabilized samples. All tests for the stabilized samples were undertaken at optimum moisture content and maximum dry density. The engineering properties of the control dispersive soil sample are shown in Table 1.

Table 1. Engineering properties of the dispersive soil

\begin{tabular}{l|l}
\hline Characteristics & Quantity measured \\
\hline Plasticity Index (PI) \% & 9 \\
Plastic Limit (PL) \% & 20 \\
Liquid Limit (LL) \% & 29 \\
Shrinkage limit (SL) \% & 5 \\
$\begin{array}{l}\text { Soil classification (AS 1726- } \\
\text { 2017) }\end{array}$ & SP-SM \\
Maximum dry density kg/m ${ }^{3}$ & 2120 \\
$\begin{array}{l}\text { Optimum moisture content } \\
\text { (OMC) \% }\end{array}$ & 12.5 \\
$\begin{array}{l}\text { Unconfined compression strength } \\
\text { (MPa) }\end{array}$ & 0.13 \\
Pinhole classification & D2- Dispersive
\end{tabular}

Emerson Class Number 1- Complete
dispersion

The stabilizing agents (Lime, Cement and Fly ash) were sourced from a local supplier (Boral Ltd.) in Victoria, Australia [14, 32]. Each of these admixtures used complied with the relevant Australian Standard namely Portland cement AS 3972, hydrated lime with AS 1672-1997 and class F fly ash conforms to AS 3582.1 standards as per project requirement. The chemical composition of the LCF admixtures is presented in Table 2 .

Table 2. Chemical composition of sodic soil stabilizing additives

\begin{tabular}{c|c|c|c}
\hline Element & \multicolumn{3}{|c}{ Percentage by weight (\%) } \\
\hline & Cement & Fly ash & Hydrated lime \\
\hline $\mathrm{SiO}_{2}$ & 19.9 & 46.1 & $<2.0$ \\
$\mathrm{Al}_{2} \mathrm{O}_{3}$ & 4.6 & 25.0 & $<1.0$ \\
$\mathrm{Fe}_{2} \mathrm{O}_{3}$ & 4.0 & 7.3 & $<0.5$ \\
$\mathrm{CaO}$ & 64.3 & 8.0 & $<71.0$ \\
$\mathrm{MgO}$ & 1.7 & 1.8 & $<1.0$ \\
$\mathrm{~K}_{2} \mathrm{O}$ & 0.6 & 0.6 & 3.3 \\
$\mathrm{Na}_{2} \mathrm{O}$ & 0.2 & 4.7 & $\mathrm{ND}$ \\
$\mathrm{TiO}_{2}$ & 0.2 & 4.7 & - \\
$\mathrm{P}_{2} \mathrm{O}_{5}$ & 0.1 & 0.4 & - \\
$\mathrm{MnO}$ & 0.1 & 0.03 & - \\
$\mathrm{SO}_{3}$ & 2.6 & 0.1 & 0.9 \\
\hline
\end{tabular}

The particle size distribution (PSD) of the dry soil samples was determined in accordance to AS 1289.3.6.1 [34]. $3 \mathrm{~kg}$ of natural soil was taken and sieved using an electromechanical sieve shaker to identify the proportions of soil particles and gradation parameters. The control sample consisted of Gravel $41.8 \%$ and Sands $50.7 \%$ Clay/silt: $7.5 \%$ ). It had a coefficient of uniformity $(\mathrm{Cu}: 36.25)$, coefficient of curvature $(\mathrm{Cc}: 0.110)$ and was classified SP-SM. The corresponding PSD curve is displayed in Figure 1.

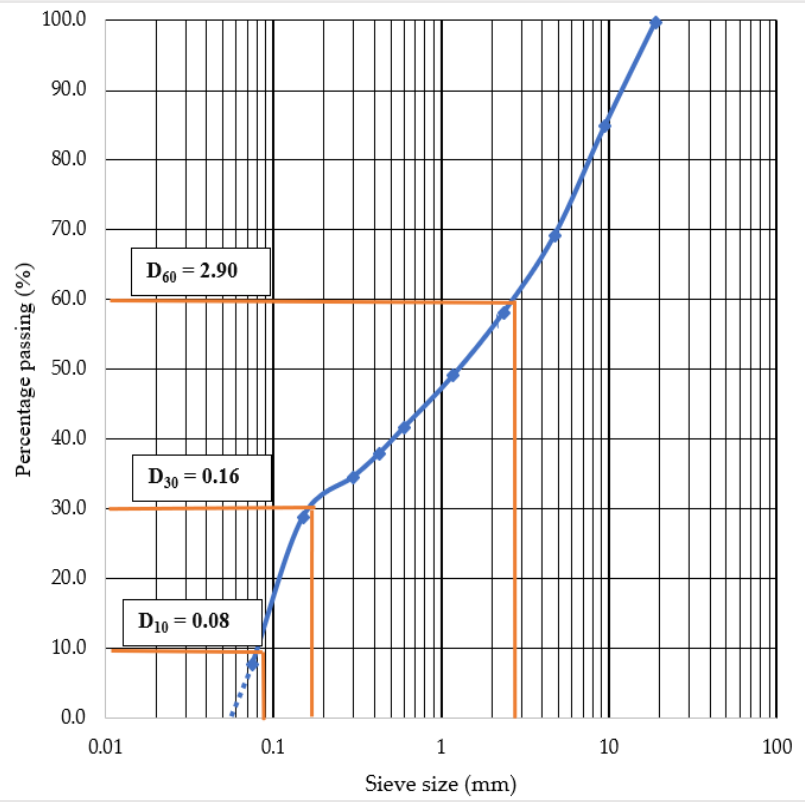

Fig, 1. Particle size distribution of virgin sodic soil

The proportions for four different blends of soil samples were prepared based on [18] various dosages of lime, cement, and fly ash (LCF) as presented in Table 3. The soil blends were mixed with total stabilization contents (TSC) of $2 \%$ and $4 \%$. Each blend was prepared by drying $2.45 \mathrm{~kg}$ of soil and 
breaking down the soil lumps until it passes through a $10 \mathrm{~mm}$ screen as mentioned in AS 1289.1.1 [35]. The soil was initially mixed with the calculated amount of lime and half of the targeted moisture content. The soil-lime mixture was allowed to mellow in a humidity-controlled environment for a curing period of 48 hours in accordance to the Australian Standard. After curing, cement and fly ash additives were then added to form an LCF blend. During the second mixing, the soil was uniformly ground using a large electric mixer and remaining half of the targeted moisture content was added.

Table 3. Triple Blend stabilisation mix proportions

\begin{tabular}{c|c|c|c}
\hline Blend & $\begin{array}{c}\text { Lime } \\
(\mathbf{\%})\end{array}$ & $\begin{array}{c}\text { Cement } \\
\mathbf{( \% )}\end{array}$ & $\begin{array}{c}\text { Flyash } \\
\mathbf{( \% )}\end{array}$ \\
\hline Blend 1 & 30 & 40 & 30 \\
Blend 2 & 25 & 40 & 35 \\
Blend 3 & 20 & 50 & 30 \\
Blend 4 & 20 & 40 & 40 \\
\hline
\end{tabular}

\subsection{Macro and micro-level tests}

\subsubsection{Modified Proctor compaction test}

Compaction tests were conducted over a broad range of moisture contents $(5 \%$ to $17 \%)$ such that the maximum mass of dry soil per unit volume was achievable during optimum moisture content (OMC) and Maximum Dry Density (MDD) for soils passing through $19 \mathrm{~mm}$ sieve. For each triple blend mix, Modified Proctor Compaction was undertaken according to AS 1289.5.2.1 [25] instead of Standard Proctor Compaction [26]. This is because heavier hammer weight, increased number of layers and longer drop distance involved in Modified Proctor procedures result in more compaction energy. This leads to a reduction in void space; therefore, maximum unit weight can be achieved using less water [3637]. Once the compacted soil was extruded, smaller quantities of approximately $100 \mathrm{~g}$ were weighed and placed in drying oven for 24 hours to obtain the moisture contents as per 1289.2.1.1 [38].

\subsubsection{Atterberg Limits and Unconfined Compression Strength Tests}

Atterberg limits and UCS tests were performed to obtain the geotechnical properties of each blend. UCS tests were performed according to AS 5101.4 [39] for both natural and stabilized soil samples and the results were compared. The UCS test setup is illustrated in Figure 2(a). In order to reduce the standard error and for greater accuracy, the average of three tests was considered. All the samples were cured in snap-lock bags that are available with industrial heavy-duty press seals compliant with AS 4376-2006. A 28-day mellowing period was considering all test cases without any loss of moisture.

\subsubsection{Pinhole dispersion and Emerson Class tests}

Emerson class test classifies soil based on a visual assessment of deflocculating underwater, while Pinhole test helps to classify the soil based on the color of the water released from different pressure heads to pass through the sample for specified time periods. Emerson class test was performed on both unmixed and stabilized soil samples following AS 1289.3.8.1 [27]. Similarly, Pinhole dispersion test was performed for the natural soil and the blended soil in accordance to AS 1289.3.8.3 [28]. This test was used to categorize the dispersive characteristic of a fine-grained compacted sodic soil. The specimens are prepared from soil grains passing through $2.36 \mathrm{~mm}$ aperture sieve and the overall test set up is shown below in Figure 2(b).

\subsubsection{Scanning Electron Microscopy (SEM) and X-ray Diffraction (XRD) Analyses}

Once the physical parameters were analyzed, SEM was used to analyze the micro-level changes occurring as a result of the stabilization process in the dispersive soil blends using the FEI Tecnai F30 SEM at Bio 21 Advanced Microscopy Facility in University of Melbourne, Australia. The SEM analysis mainly observed the formation of hydration products such as ettringite crystals and C-S-H compounds. X-Ray diffraction (XRD) measurement is a non-destructive and a powerful analytical method to identify the identify the elemental composition based on material structure interaction. XRD analysis was performed on the unmixed soil as well as Blend 3 sample with $4 \%$ TSC to study the changes in the soil mineralogy after stabilization. The test setup for SEM and XRD analysis is presented in Figure 2(c).

\section{Results and Discussion}

\subsection{LCF stabilisation in enhancing the Geotechnical properties}

\subsubsection{Compaction test results}

Figure 3 represents the results from OMC and MDD curves obtained from 9 different compaction tests with $2 \%$ and $4 \%$ TSC. B1 and B3 mixes were designed to account for higher cement content, whereas B2 and B4 contained more fly ash content to simulate practical conditions similar TMR's road project [17]. Modified Proctor Compaction (OMC) test results indicated that the OMC parameter increased with increase in the percentage of stabilizer replacement and was found to be directly proportional to the water-demand characteristic as previously reported by Mohammed [40] and Phanikumar [13]. However, the B2 and B4 with 2\% TSC were observed to have a significantly higher water demand characteristic to reach OMC than that of $4 \%$ TSC. This variation can be directly attributed to the presence of higher fly ash proportions in these blends. Therefore, the variation in experimental outcomes corelate to the fact that fly ash containing high number of electrolytes increases the hydraulic activity in the soil at lower doses [40]. Thus, the compaction test results prove that the addition of larger quantities of fly ash stabilizer increases the amount of OMC water requirement in case of a blended sodic soil.

It is noted from Figure 3(a), that for the $2 \%$ TSC, the 4 blends exhibit distinct responses as the moisture content varies from $5 \%$ to $17 \%$. While $\mathrm{B} 1$ and $\mathrm{B} 2$ exhibit similar behavior a more distinct disparity is noted in B3 and B4. At $4 \%$ TSC, B2 and B3 exhibit a very similar behavior as the moisture

\subsubsection{Atterberg limits}

The Atterberg results provided an interesting insight to the geophysical properties of LCF stabilized strongly sodic soil where the swell-shrink properties were significantly lowered due to increase in blend proportions. The LL and PL for B1, $\mathrm{B} 2$ and B3 increased with lower shrinkage observed for $4 \%$ TSC when compared to $2 \%$ TSC. This exhibits that the swellshrink behavior of sodic soils was restricted with the addition of $4 \%$ TSC. However, Blend- 4 having a higher fly ash content showed, lower LL and PL values for 4\% TSC. The linear shrinkage values were lowest in B1-4\% followed by B4-4\% 
Raghavendra Vasudeva Upadhyaya, Jerome Akpoge Egwurube, Prince Bhandari, Prasad Gudimetla and Angela Rengifo/ Journal of Engineering Science and Technology Review 14 (3) (2021) 167 - 178

with the reduction factor being $2.1 \%$ approximately. However, the Plasticity Index were observed to be lower in all blends with 4\% TSC signifying that the higher soil stabilizer replacement content for sodic soil will reduce the PI and vice versa. Further, B-3 possessing greater cement ratio amongst all blends had the lowest Plasticity Index (PI=LL-

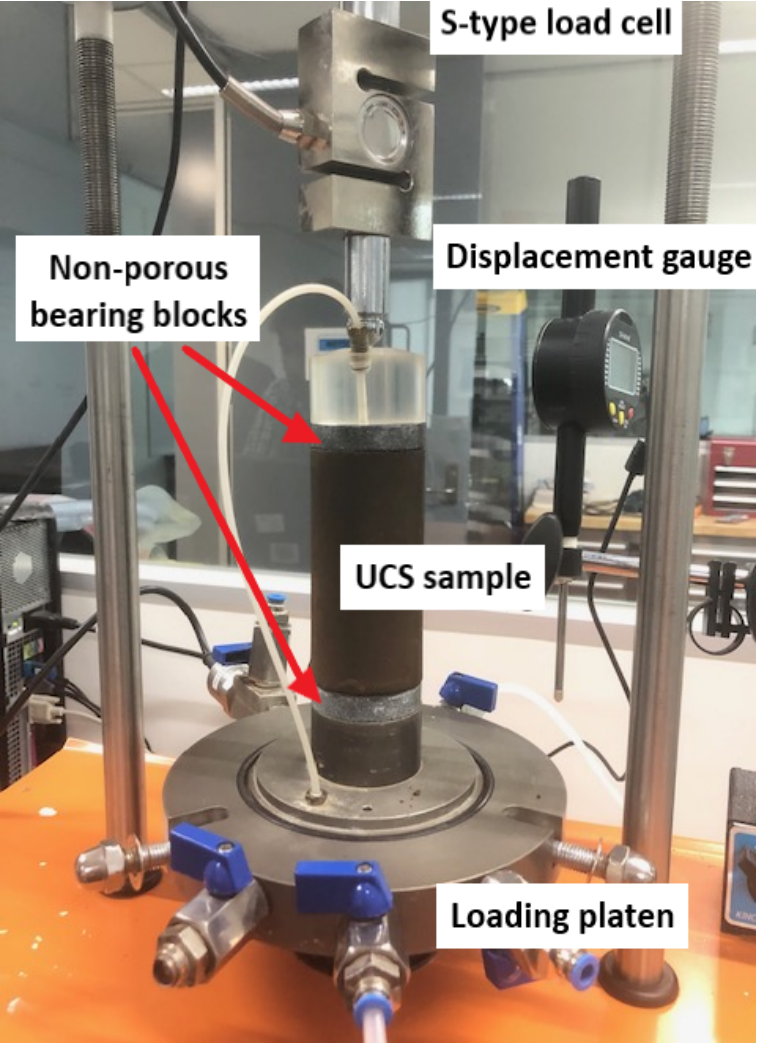

(a)
$\mathrm{PL})$ at $4 \% \mathrm{TSC}$ when compared to its counterparts. The Atterberg parameters obtained for individual blend ratios are presented in Table 4.

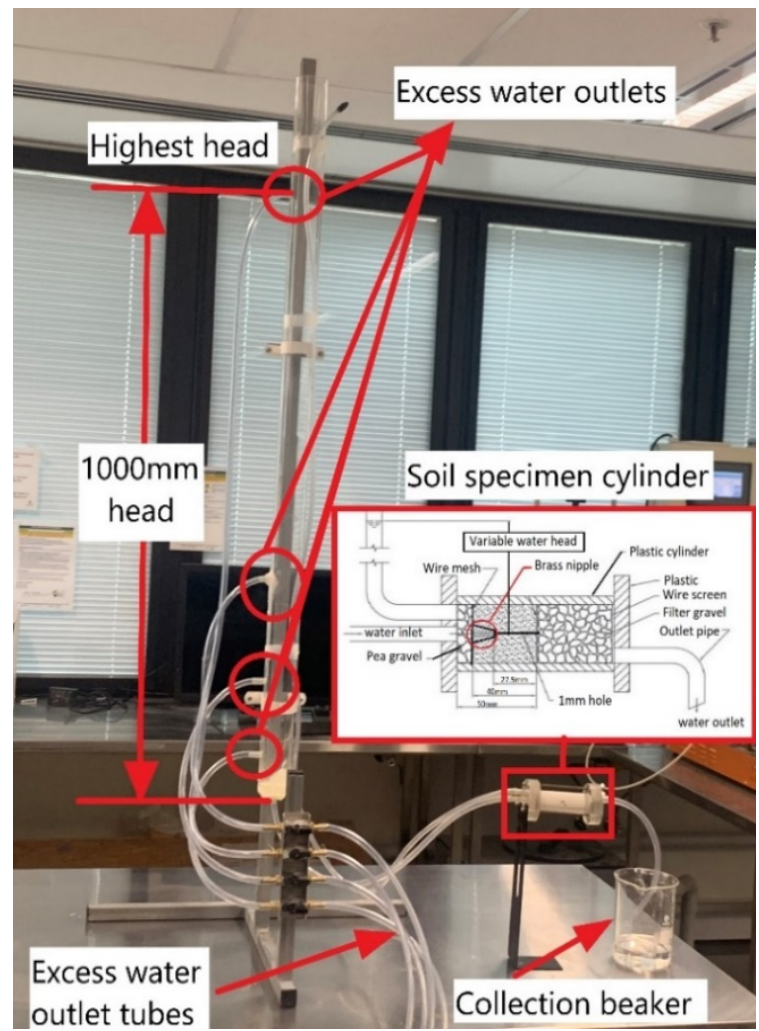

(b)

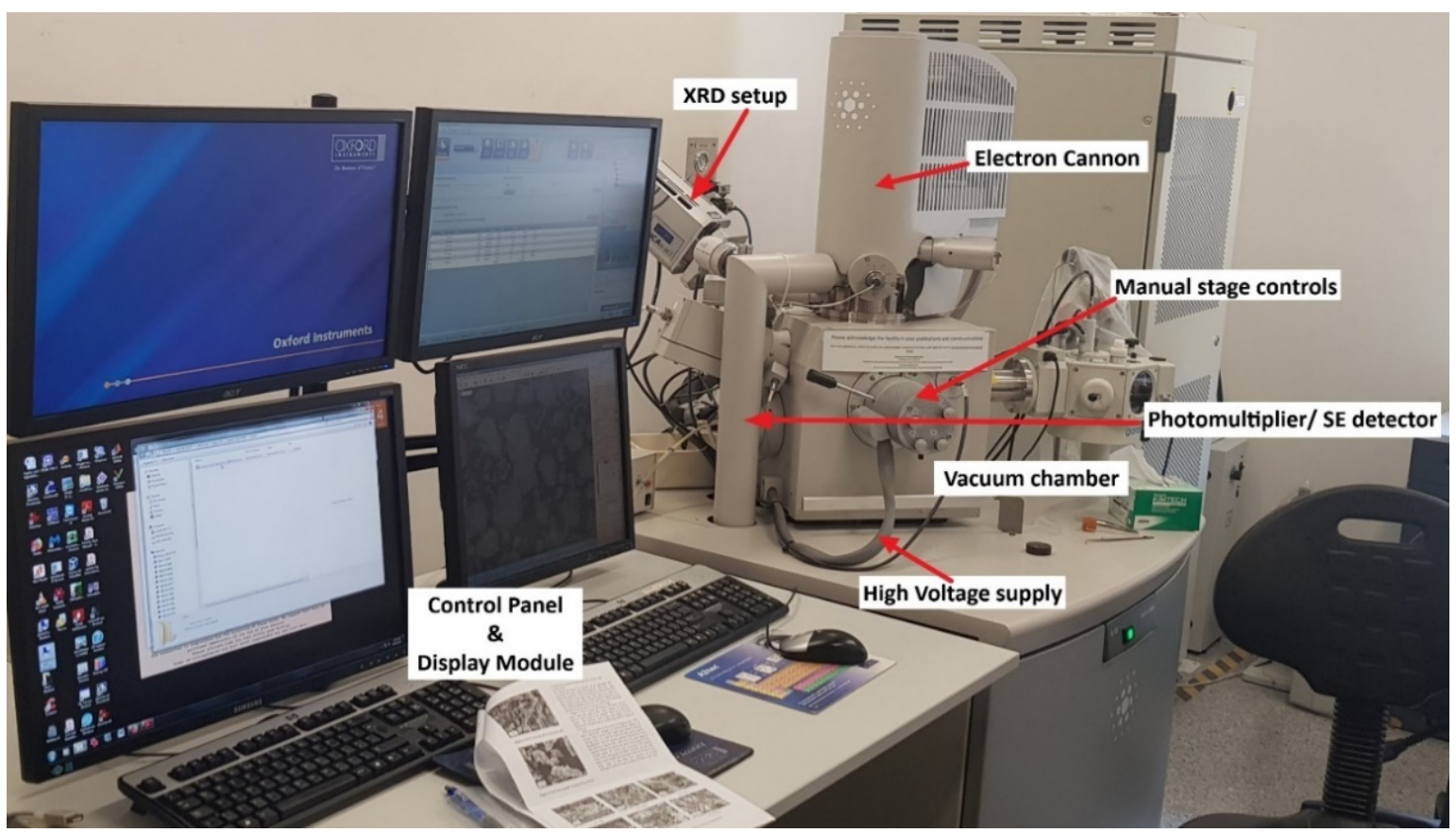

(c)

Fig. 2. Experimental setup for macro and micro-level analyses: (a) UCS test setup; (b) Pinhole test setup; (c) Scanning Electron Microscopy and X-Ray Diffractometry testing 


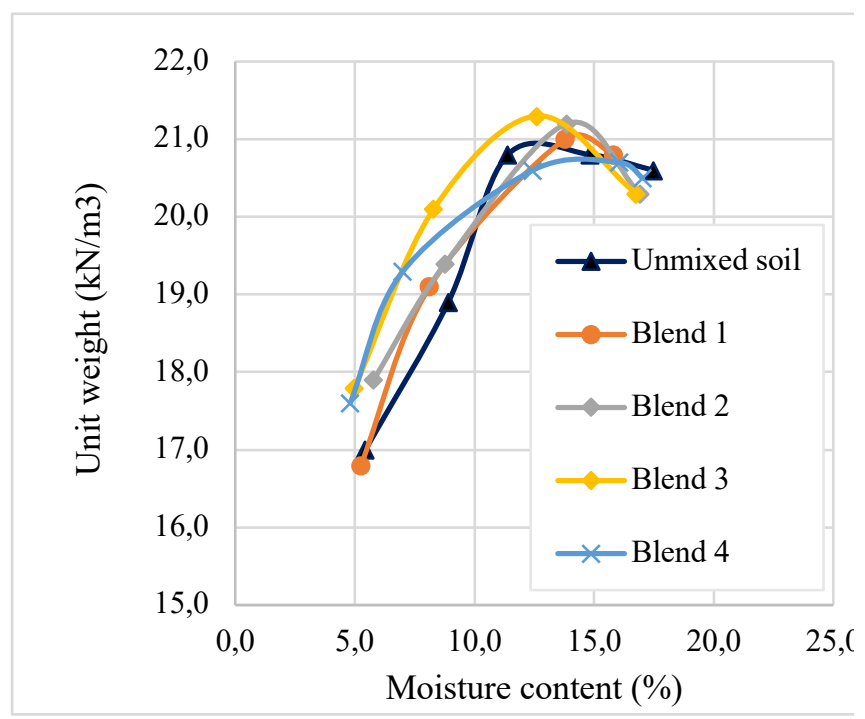

(a)

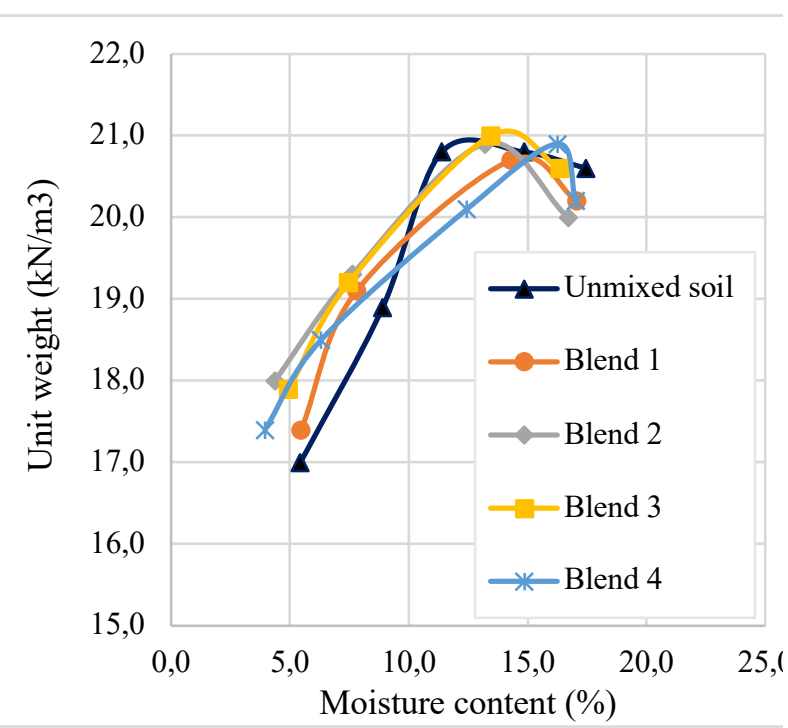

(b)

Fig. 3. Comparison of OMC and MDD results for all blends from Modified Proctor Compaction: (a) 2\% TSC; (b) $4 \%$ TSC

Table 4. Atterberg limits for soil specimens

\begin{tabular}{c|c|c|c|c|c|c}
\hline Soil blend & LL (\%) & PL (\%) & PI (\%) & LS (\%) & OMC (\%) & MDD (kg/m $\left.\mathbf{m}^{\mathbf{3}}\right)$ \\
\hline Unmixed Soil & 29.1 & 19.8 & 9.3 & 4.9 & 14.8 & 2120.1 \\
Blend 1 - 2\% & 31.6 & 23.1 & 8.6 & 3.3 & 13.8 & 2140.6 \\
Blend 1 - 4\% & 32.8 & 25.0 & 7.8 & 2.8 & 14.3 & 2114.8 \\
Blend 2 - 2\% & 33.9 & 22.0 & 11.9 & 5.4 & 13.9 & 2157.1 \\
Blend 2 - 4\% & 35.3 & 26.8 & 8.5 & 4.4 & 13.2 & 2132.6 \\
Blend 3 - 2\% & 34.6 & 26.6 & 8.0 & 5.8 & 12.6 & 2171.1 \\
Blend 3 - 4\% & 34.7 & 32.4 & 2.3 & 5.7 & 13.5 & 2137.4 \\
Blend 4 - 2\% & 33.7 & 26.1 & 7.7 & 3.5 & 16.1 & 2111.0 \\
Blend 4 - 4\% & 33.3 & 25.9 & 7.4 & 2.9 & 16.3 & 2126.4 \\
\hline
\end{tabular}

The LS value for this project was greater than 6 , therefore, the blend (L-40\%, C-30\%, and F-30\%) was chosen according to TMR specification benchmark [18].

\subsubsection{Unconfined compressive strength test}

Unconfined compressive strength test is a procedure to determine the compressive strength of the soil sample. The stabilized soil samples were subjected to UCS test at a constant displacement rate of $1.0 \mathrm{~mm} / \mathrm{min}$ as per [39]. To maximize the accuracy during the test, an average of 3 values were considered for each blend with 27 tests performed overall. The un-stabilized soil attained a UCS of $0.13 \mathrm{MPa}$ and therefore tested with varying LCF proportions to achieve the desired strength of 1.3 to $1.5 \mathrm{Mpa}$ proposed specification by TMR Australia for road construction.

For the proposed blends, the maximum unconfined compressive strength obtained was $0.86 \mathrm{MPa}$ for blend 4 and $0.60 \mathrm{MPa}$ for B3, both results with a total stabilization content of $4 \%$ at 28 days curation period and 48 hours mellowing time. Although the UCS of all the blends had significant strength improvement at 4\% TSC, none satisfied the proposed specification. It was observed that with constant cement stabilization content of $40 \%$, UCS increases with increasing proportion of fly ash. A $10 \%$ increase in fly ash (B4) corresponded to an increase of $68.7 \%$ at $2 \%$ TSC and $42.2 \%$ at $4 \%$ TSC in UCS whereas a $10 \%$ increase in cement (B3) corresponded to $43.4 \%$ at $2 \%$ TSC and $14.2 \%$ at $4 \%$ TSC when compared to B2. The average of three UCS values was taken as the final reading. Figure 4 illustrates the projected stabilization content required to achieve TMR specification of $1.5 \mathrm{MPa}$.

The regression analysis shows that $\mathrm{B} 4$, being the strongest blend, requires only a small addition of TSC $(2.53 \%)$ to achieve 1.5 MPa strength whereas B2 tends to be the weakest requiring $5.07 \%$ supplementary stabilizers to achieve the target strength. On the other hand, B1 and B3 required 4.09\% and $4.52 \%$ TSC respectively. Class F fly ash seemed to have increased the pozzolanic reactions of the blend enhancing bonding between soil particles. In addition, elastic moduli for all blends and the unmixed samples were calculated from stress-strain parameters from the UCS tests. The highest elastic modulus was found to be $88 \mathrm{MPa}$ for B4 at $4 \%$ TSC which is approximately 13.6 times greater than that of unmixed soil as presented in Figure 5 signifying its stiffness properties towards resisting excessive subsoil deformations and an indication of higher factor of safety. 


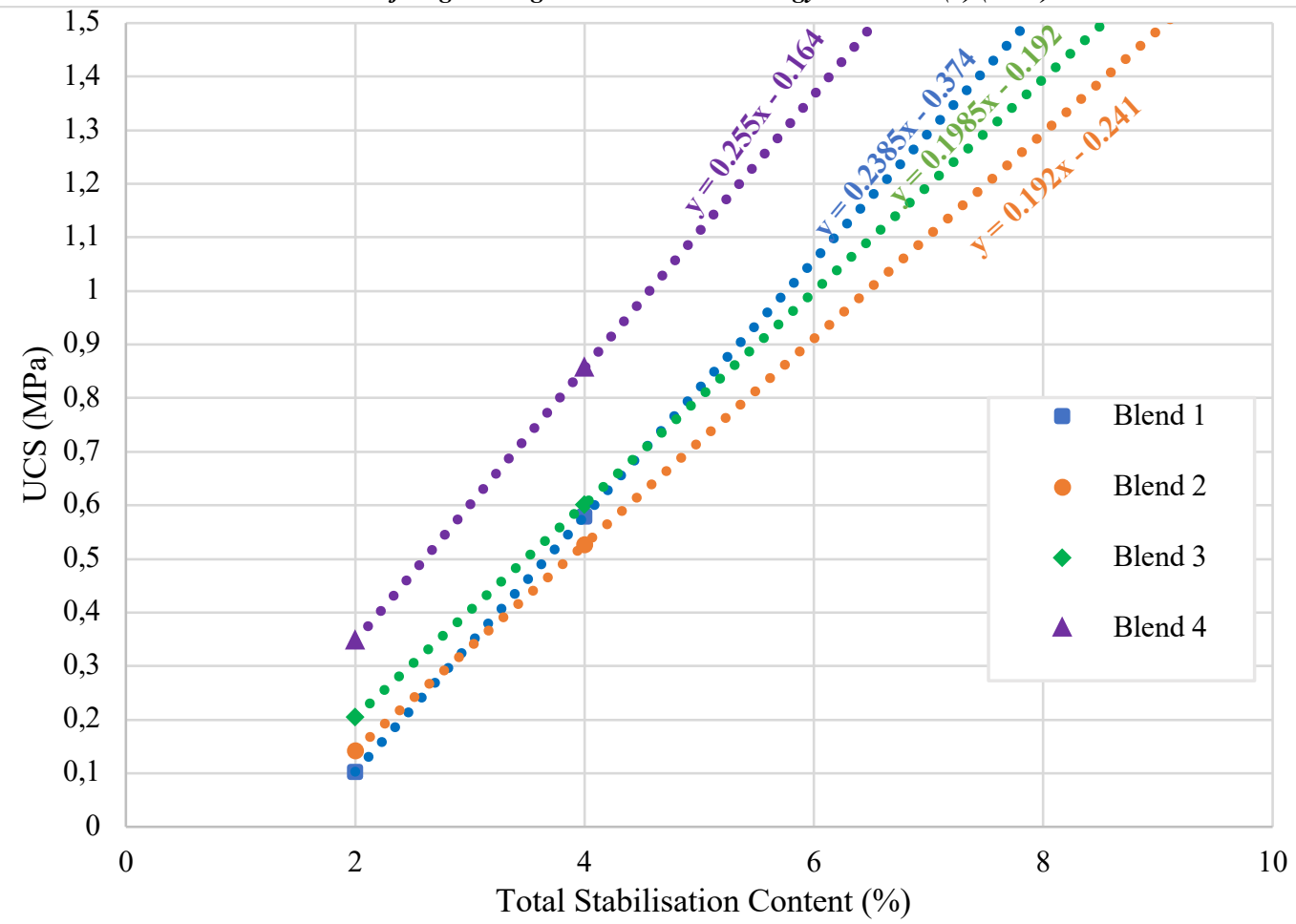

Fig. 4. Strength performance for LCF triple blend stabilization of sodic soil

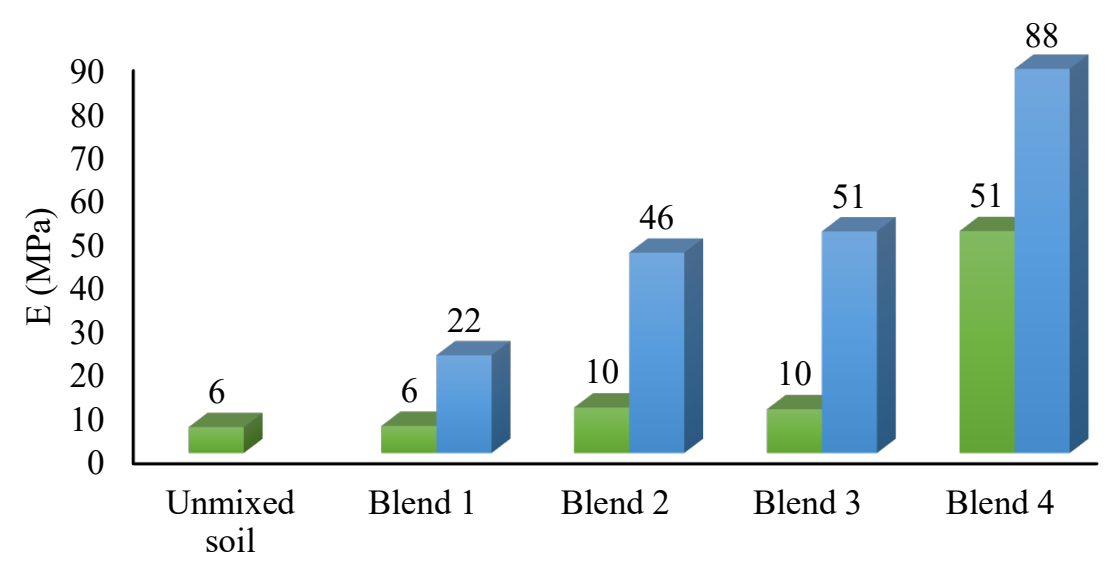

$$
\square \text { TSC } \quad 4 \% \mathrm{TSC}
$$

Fig. 5. Elastic modulus estimation for various blends from stress-strain parameters

\subsubsection{Influence of Mellowing Period on UCS}

The time allowed to cure the sample after mixing the stabilizing agents is known as mellowing time and has a direct impact on soil strength attainment [41]. It is also known as amelioration period, rotting period or ageing period and is classified as the interval between mixing and compaction stages for stabilized soils [42]. Despite B4 achieving the highest UCS performance, it did not satisfy the minimum strength requirement proposed by TMR under 48 hours of mellowing. In accordance to the Australian standard AS 5101.4 [39], if curing time is not specified prior to compaction, samples containing lime shall be cured for 48 to 72 hours whereas for samples containing GP cement shall be cured for 2 to 3 hours. A random trial was conducted to investigate the effect of zero mellowing time with respect to 48 hours during the addition of stabilizing agents. In case of B3 - 4\% TSC, the UCS results showed significant upsurge $(1.60 \mathrm{MPa})$ in contrast to the original achieved value of 0.60
MPa when the samples were mixed with lime, cement, fly ash and OMC altogether and allowed to cure for 28 days. This might be because the $\mathrm{C}-\mathrm{S}-\mathrm{H}$ bonding development initiates between soil and lime within the mellowing period, which is broken due to further mixing of other additives at later stages of blending. Also, if the compaction is delayed which means if mellowing time is allowed, apart from the early bonding development, moisture might be lost during that time which might affect the level of compaction to be attained and hydration rate.

\subsection{Effects of triple blend stabilisation in the dispersivity of soil}

\subsubsection{Emerson class test}

Emerson class test and Pin-hole test were carried out to determine the final performance in the dispersivity of blended soil with respect to the control sample. This test consisted of 
the visual assessment of soil particles to deflocculation in water. For each blend stabilized soil, three soil crumbs retained on $2.36 \mathrm{~mm}$ sieve were taken and mixed with $200 \mathrm{ml}$ of water and were observed for a period of 10 minutes as recommended in AS 1289.3.8.1. Once the crumbs were placed into the water, it was noticed that the colloidal cloud of unstabilised soil covered the beaker bottom within 10 minutes. According to the used standard, this soil was designated as number 1 which represented high dispersion. Figure 6 and Figure 7 shows the dispersion tests procedures and outcomes for the unstabilised soil and stabilized soil respectively.

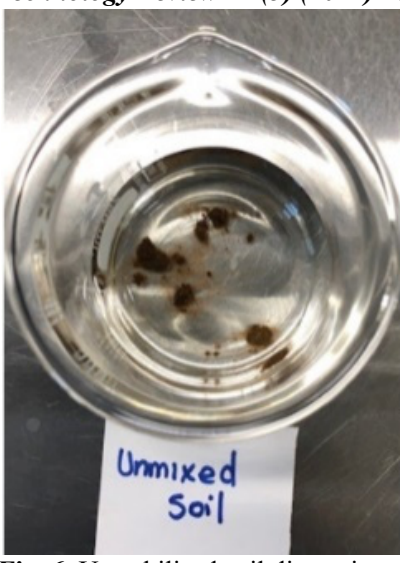

Fig. 6. Unstabilised soil dispersion

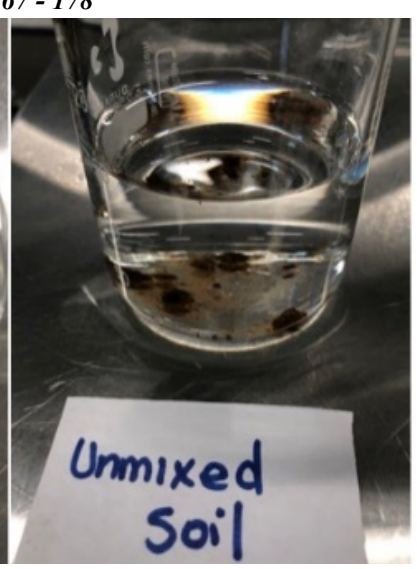

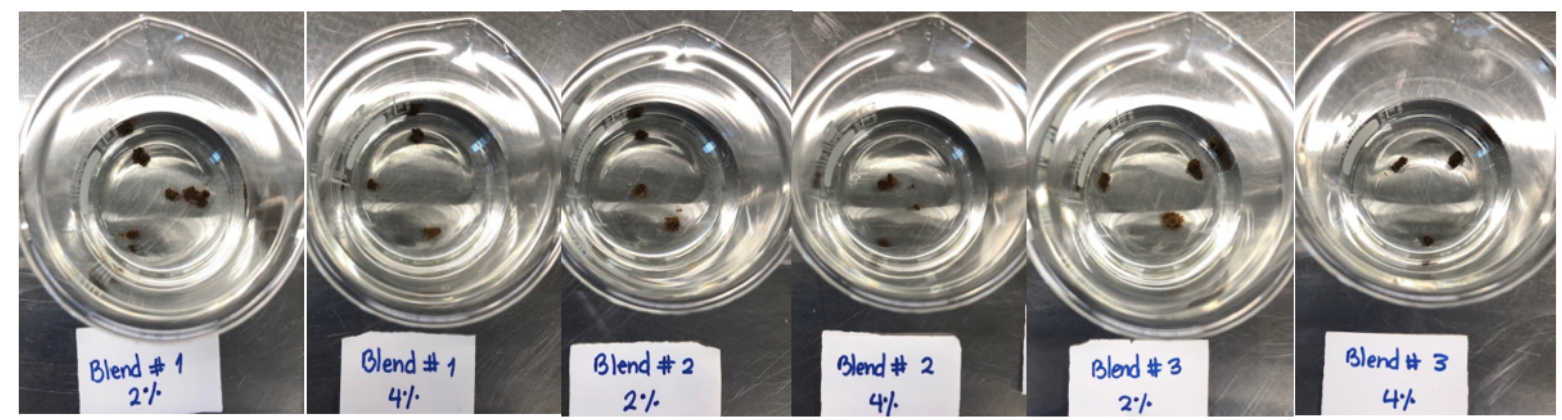

Fig. 7. Emerson class test results

Emerson class test classification has been divided into 8 categories as presented in Table 5.

Table 5. Emerson Class test classification

\begin{tabular}{c|l}
$\begin{array}{c}\text { Emmerson } \\
\text { Number } \\
\text { Class }\end{array}$ & \multicolumn{1}{c}{ Description } \\
\hline 1 & Complete Dispersion \\
2 & Some Dispersion \\
3 & Dispersion after remolding \\
4 & No Dispersion (Calcite or gypsum present) \\
5 & Dispersion after soil water suspension \\
6 & Flocculation \\
7 & Swelling (Not slaking) \\
8 & Not swelling (Not Slaking) \\
\hline
\end{tabular}

As seen in Figure 7, all the blends with $2 \%$ and $4 \%$ TSC showed no dispersion and were grouped under Class 4 on the Australian Emerson scale.

Table 6. Soil classification based on Pinhole dispersion test

\begin{tabular}{|c|c|c|c|c|c|}
\hline \multicolumn{2}{|c|}{ Classification $^{1}$} & \multirow{2}{*}{$\begin{array}{l}\text { Head at the } \\
\text { termination of } \\
\text { test }(\mathbf{m m})\end{array}$} & \multirow{2}{*}{$\begin{array}{l}\text { Test time } \\
\text { of head } \\
\text { (min) }\end{array}$} & \multirow{2}{*}{$\begin{array}{c}\text { Visibility of colour } \\
\text { of flow at end of } \\
\text { the test }\end{array}$} & \multirow{2}{*}{$\begin{array}{l}\text { Final flow through } \\
\text { specimen }(\mathrm{mL} / \mathrm{s})\end{array}$} \\
\hline Designation & Description & & & & \\
\hline D1 & Highly dispersive & 50 & 10 & Very distinct & - \\
\hline D2 & Dispersive & 50 & 10 & Distinct to slight & - \\
\hline PD1 & Potentially dispersive & 175 & 5 & Slight to easy visible & - \\
\hline PD2 & $\begin{array}{l}\text { Potentially dispersive } \\
\quad \text { (intermediate) }\end{array}$ & 350 & 5 & Slight & $>3.5$ \\
\hline ND1 & Non-dispersive & 1000 & 5 & $\begin{array}{l}\text { Slight to barely } \\
\text { visible }\end{array}$ & $>5$ \\
\hline ND2 & $\begin{array}{l}\text { Completely erosion } \\
\text { resistant }\end{array}$ & 1000 & 5 & Clear & $>5$ \\
\hline
\end{tabular}

\footnotetext{
${ }^{1}$ Table 12, [38].
}

\subsubsection{Pinhole test}

Pinhole test is one of the most the commonly used reliable and quick method to examine the dispersivity of the soil [43]. The stabilized soils were also subjected to pinhole test where dispersive characteristics were improved and were classified as completely erosion-resistant which is further discussed in the results portion. This test is performed by circulating a flow of water through a small hole of $1 \mathrm{~mm}$ diameter made into the soil sample under the varying head of water [2]. The test was performed on both un-stabilized soil and the triple blend stabilized soil according to the relevant Australian Standard. The test results showed that the additives inhibited the dispersivity characteristics of the stabilized soil. Naturally available sodic soil was classified as D2 where head at test termination was at $50 \mathrm{~mm}$ and flow wasn't clearer until 10 mins. D2 represents that the soil was dispersive in nature according to Table 6 in the AS 1289.3.8.3: 2014. 
It was observed that unblended sodic soil was not displaying clear flow within the initial 5 minutes of commencing the trial. According to the standard, the test was repeated with an additional 5 minutes where the flow became cloudier as anticipated and the soil was seen to be eroding. Therefore, the test was terminated with a constant head of 50 $\mathrm{mm}$ and the soil was classified as D2 meaning dispersive in nature. On the other hand, all treated soils showed nondispersive behavior and were classified as completely erosion resistant (ND2). This was corresponding to the results verified

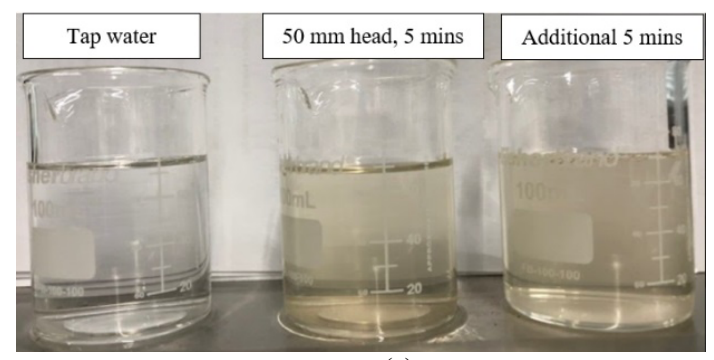

(a) during Emerson class test. A steady flow of water level was maintained even with the additional time and the collected water was found to be clear with no suspended particles. This proved that all blends of stabilized sodic soils were completely erosion resistant with head at termination of the test being $1000 \mathrm{~mm}$. All the samples treated with triple blend showed the same characteristics. Figure 8(a) Figure 8(b) shows the water flow characteristics through the unblended and blended sodic soils.

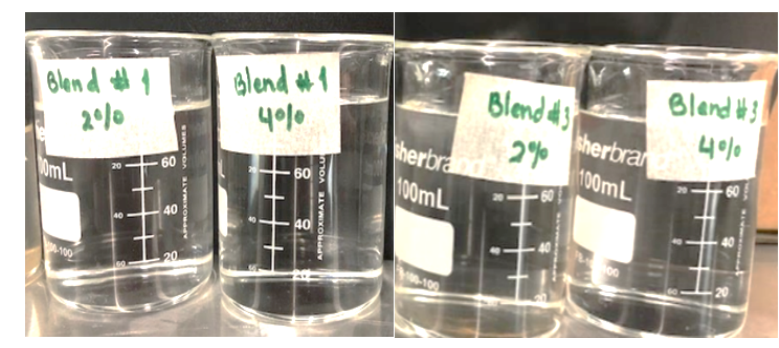

(b)

Fig. 8. Water collected from Pinhole test for specimen blends B1 and B3

\subsection{Qualitative analysis of sodic soil stabilization}

\subsubsection{Scanning Electron Microscopy (SEM)}

Micrographs obtained from Scanning Electron Microscopy (SEM) analysis were studied to understand the growth of LCF bonding morphology over strongly sodic soil stabilization. Changes in the soil structure where the formation of fabrics and ettringite needles were noticed. Figure 9 shows a microphotograph of the unmixed soil sample where there is no noticeable affinity between the soil particles.

Figure 10(a) and Figure 10(b) show SEM microphotographs of samples from $4 \%$ TSC B1 and B2 blends with pronounced formation of ettringite crystals due to the greater availability lime stabilizer. Ettringites are needle-

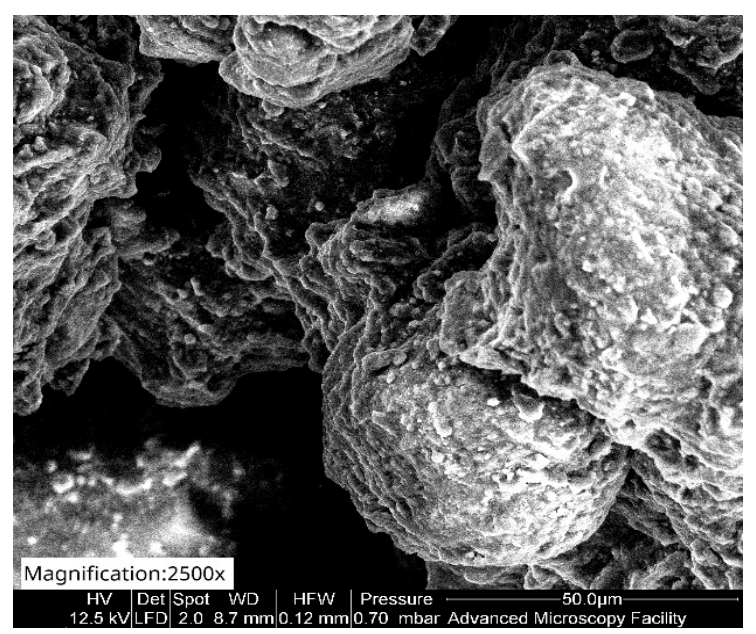

(a)

like crystals which are normally formed under alkaline conditions $\left(\mathrm{CaCO}_{3}\right)$ of soil with high activities of $\mathrm{Ca}^{++}, \mathrm{SO}_{4}{ }^{-}$ - and $\mathrm{Al}^{+++}$[44-45]. Likewise, Figure 10(c) and Figure 10(d) illustrates C-S-H net-like structures in the B3 and B4 with 4\% TSC from fly ash cluster, thus initiating accelerated pozzolanic reaction. It can be concluded that blends with $2 \%$ TSC contributed to the formation of only ettringites crystals whereas blends with higher TSC of $4 \%$ result in C-S-H fabrics. Moreover, the fly-ash increases the pozzolanic reaction as it consists of spheres of silicon, aluminum, iron oxides and unoxidized carbon which forms the CSH or CAH when mixed with lime, cement and water enhancing the bonding between soil particles [11].

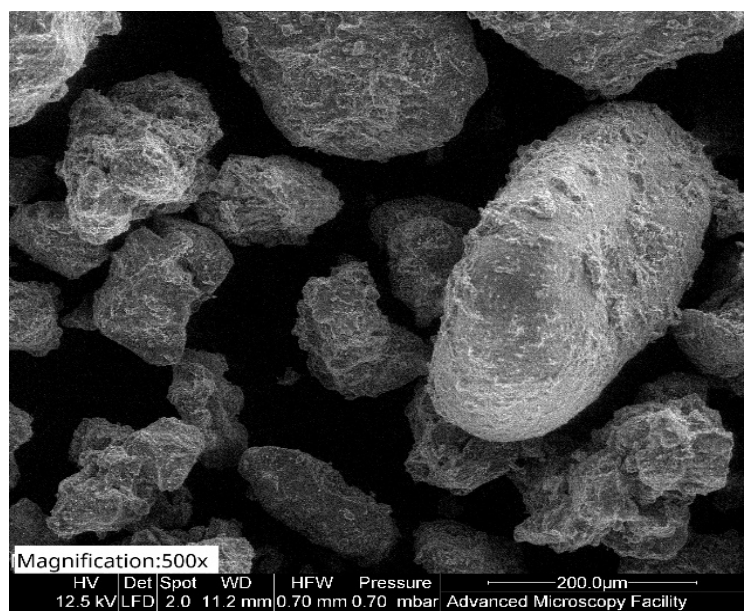

(b)

Fig. 9. Micrographs for soil specimens with no additives (a) Unmixed soil $2500 \times$ Magnification (b Unmixed soil $500 \times$ Magnification

It can be clearly seen that the microstructural formation in B3 which has higher cement quantity with TSC $4 \%$ achieved a greater extent of $\mathrm{C}-\mathrm{S}-\mathrm{H}$ as well as ettringites formation. Similar SEM results were outlined previously by Kodikara J. where the binder with higher cement content will significantly grow the quantity of hydrated materials at a faster rate than other binders with similar curing periods [16]. In case of other blend proportions, the formation of C-S-H is not quite visible or is very low in content. Figure 11 presents the timeline for growth of C-S-H and C-A-H compounds for B3-4\% and zero mellowing time. The triple blend sampling intervals were 1day, 7-day, 14-day and 28-day period and regularly tested for its unconfined compressive strength. 
Raghavendra Vasudeva Upadhyaya, Jerome Akpoge Egwurube, Prince Bhandari, Prasad Gudimetla and Angela Rengifo/ Journal of Engineering Science and Technology Review 14 (3) (2021) 167 - 178

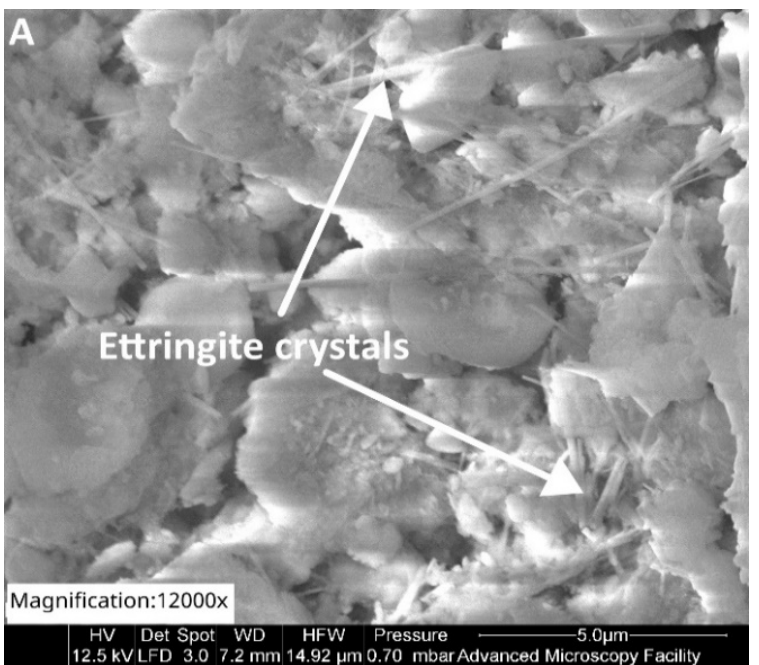

(a)

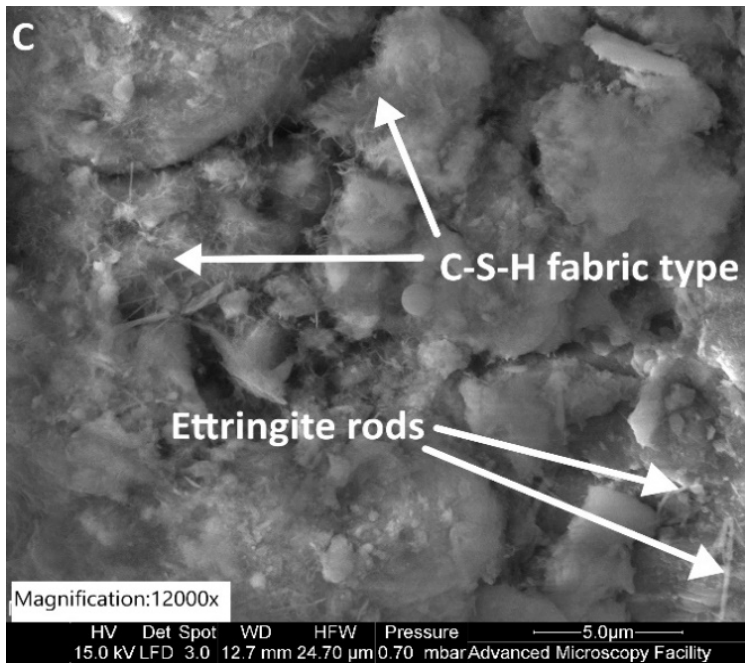

(c)

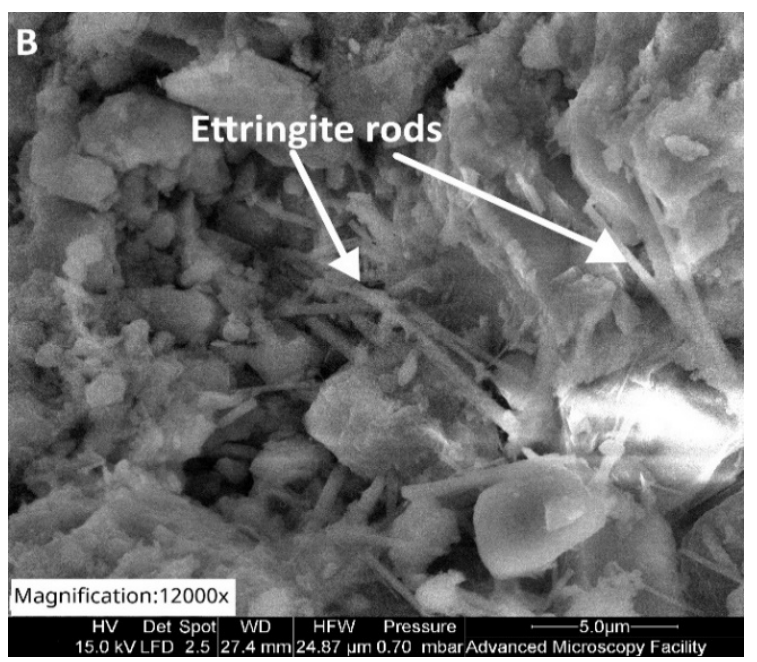

(b)

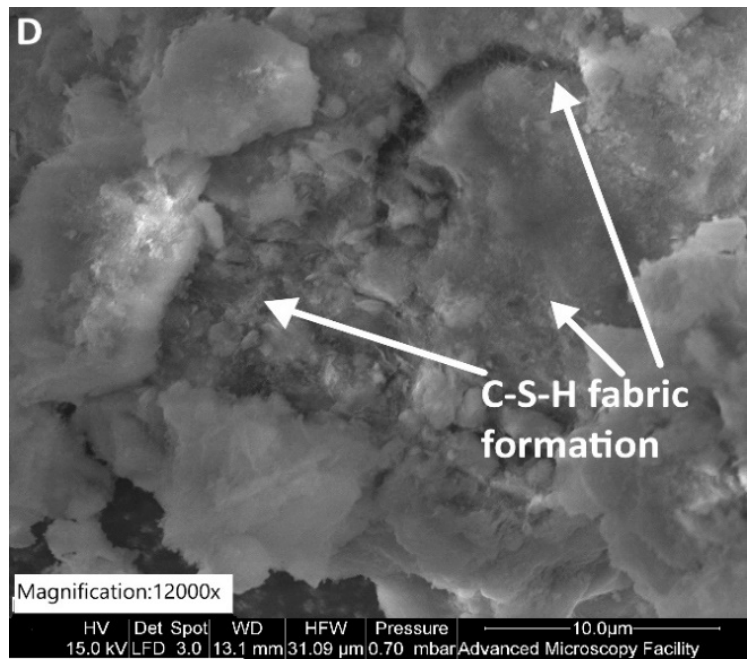

(d)

Fig. 10. SEM micrographs for post 28 days curing and 48 hours mellowing: (a) Blend 1, 2\% TSC; (b) Blend 2, 2\% TSC; (c) Blend 3, 4\% TSC; (d) Blend 4, 4\% TSC

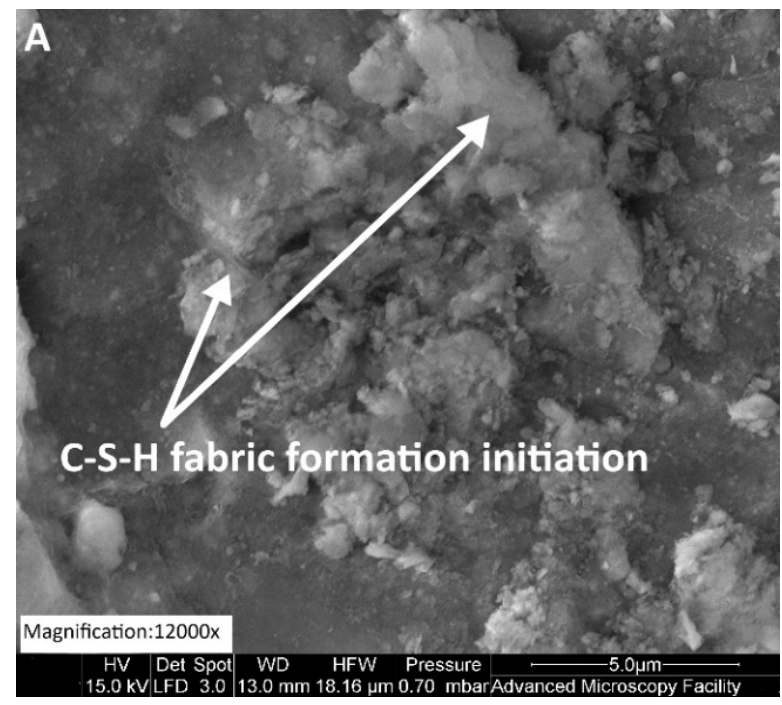

(a)

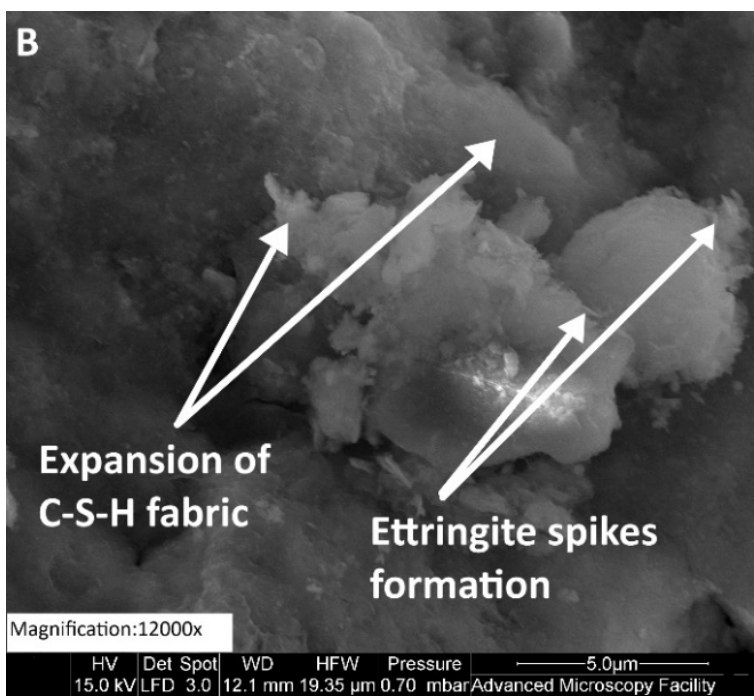

(b) 


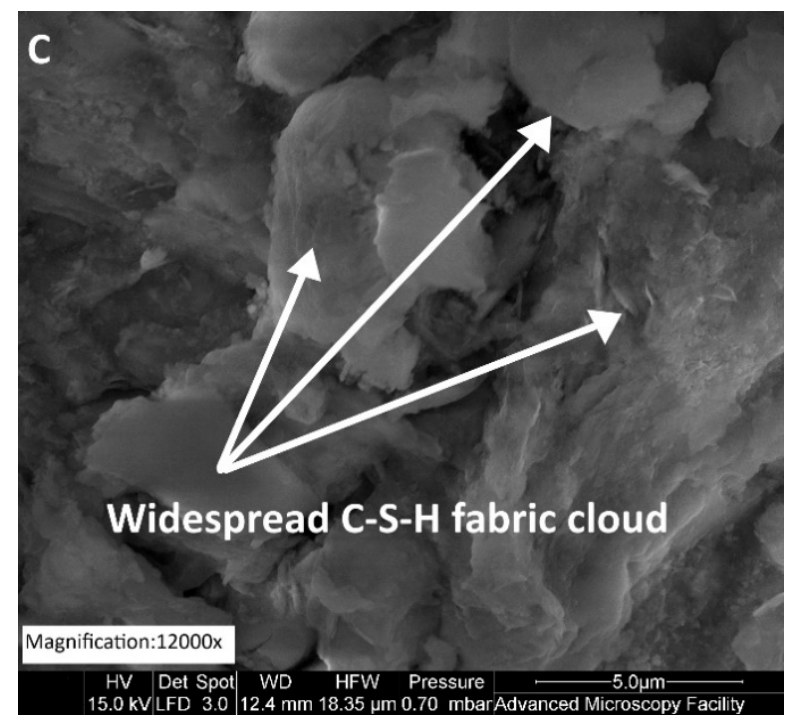

(c)

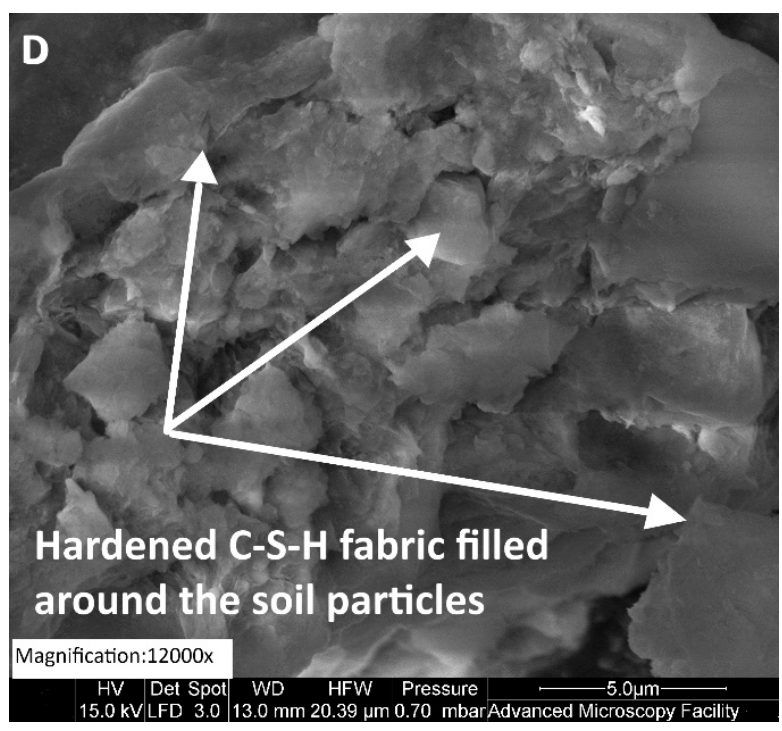

(d)

Fig. 11. SEM micrographs for Blend 3, 4\% TSC at zero mellowing: (a) 1-day curing (b) 7-days curing (c) 14-days (d) 28-days curing

In case of B3-4\% trials, the SEM micrographs revealed that the C-S-H fabric formation directly attributed towards higher strength of triple blended strongly sodic soil after 28 days with zero initial mellowing. The reason behind this consistency is that the bond generated due to zero mellowing was not subjected to breakage because of mixing the third stabilizer after 48 hours. Figure 11(a) shows the initiation of the formation of the C-S-H fabric after 1-day curing. Similarly, Figure 11(b), (c) and (d) shows the chemical reaction leading to densification of C-S-H bonds resulting in strength gain characteristics and contributing towards UCS performance. Overall, the formation of ettringites at 28 days was found to be limited in Blend 3 as it contains reduced amount of lime content in contrary to the case of 48 hours mellowing period.

\subsubsection{XRD Analysis}

XRD (X-Ray Diffraction) is a powerful tool for the mineralogical study of soil [46]. XRD performed in the unmixed soil indicated that the sodium composition was dominant as shown in Figure 11. Likewise, Figure 12 shows the XRD results of blend with $4 \%$ TSC where the stabilized soil show that $\mathrm{Ca}, \mathrm{Al}$ and $\mathrm{Si}$ as the dominant species. As discussed earlier, sodium ions are present in larger content in dispersive soil which expands in size once hydrated creating larger space between soil platelets leading to electrostatic bond breakage causing dispersion. The XRD analysis showed that the percentage of $\mathrm{Na}$ was $22.7 \%$ by weight whereas after stabilization it went down to $1.9 \%$. Similarly, Ca increased from $2.5 \%$ to $22.8 \%$ after stabilization which shows the shift of $\mathrm{Na}$ ions. The amount of $\mathrm{Si}$ and $\mathrm{Al}$ also increased significantly from $4.3 \%$ to $29.1 \%$ and $1.7 \%$ to $10.4 \%$ respectively. B4 shows higher amount of Si due to higher proportion of fly ash. Furthermore, in the stabilized soil, the oxygen content hiked due to the added moisture and oxides compounds from lime, cement, fly ash and soil minerals.

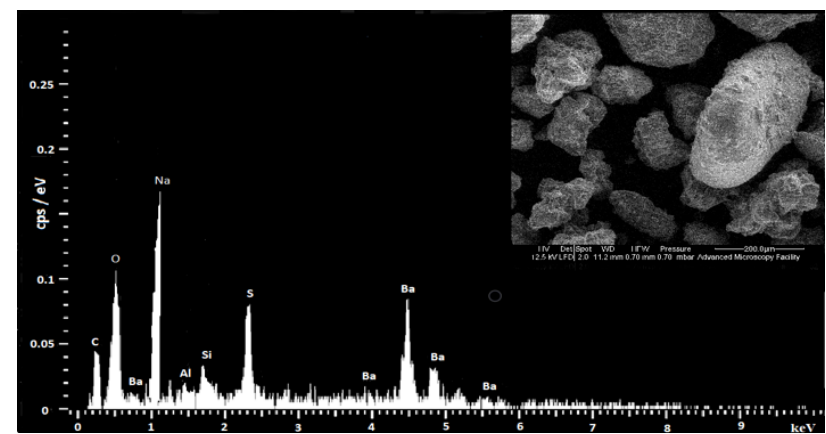

Fig. 12. XRD analysis of Unblended sodic soil

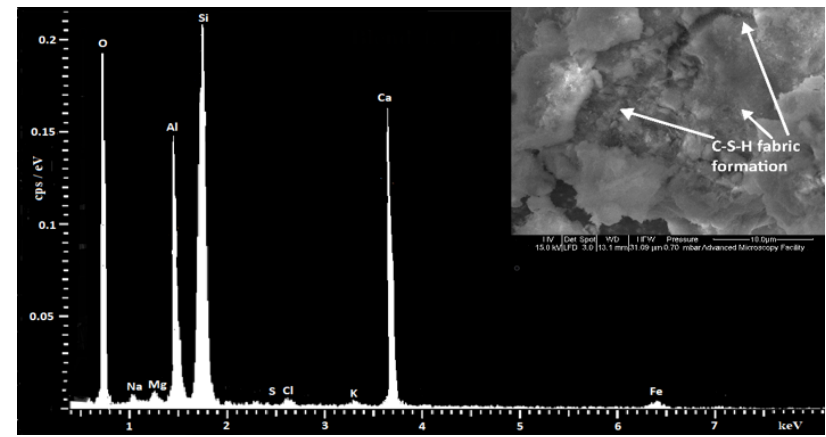

Fig. 13. XRD analysis of Blend sodic soil with $4 \%$ TSC

\section{Conclusion}

Treatment of sodic soils using proper dosage of LCF stabilizers ensures that pavement subgrade does not fail prematurely, thereby, avoiding high costs in maintenance and rehabilitation. Four different proportions of lime/cement/flyash blends were investigated in this study with blend proportions involving 30/40/30, 25/40/35, 20/40/40 and 20/50/30. The results show that UCS of the soil increased with addition of LCF stabilizers with B4-4\% TSC providing the lowest shrinkage and highest performance. Likewise, the Youngs' modulus for this blend had a growth factor of 15 when compared to unblended strongly sodic soil with an ESP of $15-25 \%$. Pinhole and Emerson class test results verified that the dispersivity of sodic soil is predominantly reduced to erosion resistant (ND2) and no dispersion (Class 2) 


\section{Raghavendra Vasudeva Upadhyaya, Jerome Akpoge Egwurube, Prince Bhandari, Prasad Gudimetla and Angela Rengifo/ \\ Journal of Engineering Science and Technology Review 14 (3) (2021) 167 - 178 \\ 5. Acknowledgments}

respectively. SEM analysis showed pronounced growth of C$\mathrm{S}-\mathrm{H}$ and ettringite matrices over curing periods ranging between 0 and 28 days. XRD analysis verified decreased $20.8 \% \mathrm{Na}$ proportion and $20.3 \%$ increase in Ca concentration. Overall, B3-4\% sample prepared under zero mellowing time recorded a $1132 \%$ increase in strength by $1.47 \mathrm{MPa}$ when compared to B3 with 48-hour mellowing. This research indicates that the triple blend stabilization technique is an innovative approach from the Australian geotechnical engineering perspective. This technique further provides a more sustainable practice by incorporating fly ash (industrial byproduct) reduces the need for the use of both lime and cement (which have to be synthesized and thus, are costly).
The authors would like to acknowledge Bio21 Advanced Microscopy Facility for supporting us with carrying out Scanning Electron Microscopic analysis. Further, the authors would like to appreciate the generous support offered by CQ University in sodic soil collection from parts of Victoria and MEL technical staff for their effort to undertake laboratory experimentations.

This is an Open Access article distributed under the terms of the Creative Commons Attribution License.

\section{References}

1. Levy, G.J., Shainberg, I. Sodic Soils. Encyclopedia of soils in the environment. 2005; 504-513. [CrossRef] https://doi.org/10.1016/B0-12-348530-4/00218-6

2. Shahid S.A., Zaman M., Heng L. (2018) Soil Salinity: Historical Perspectives and a World Overview of the Problem. In: Guideline for Salinity Assessment, Mitigation and Adaptation Using Nuclear and Related Techniques, November 43-53; 2018; 432-454. [CrossRef] https://doi.org/10.1007/978-3-319-96190-3_2

3. Abbasi, N.; Farjad, A.; Sepehri, S. The Use of Nanoclay Particles for Stabilization of Dispersive Clayey Soils. Geotechnical and Geological Engineering 2017, 36,327-335. [CrossRef] https://doi.org/10.1007/s10706-017-0330-9

4. Ouhadi, V.; Goodarzi, A. Assessment of the Stability of a Dispersive Soil Treated by Alum. Engineering Geology 2006, 85, 91-101. [CrossRef]

https://doi.org/10.1016/j.enggeo.2005.09.042

5. Sharma, N.; Swain, S.; Sahoo, U. Stabilization of a Clayey Soil with Fly ash and Lime: A Micro Level Investigation. Geotechnical and Geological Engineering 2012, 30, 1197-1205. [CrossRef] https://doi.org/10.1007/s10706-012-9532-3

6. Vakili, A.; Selamat, M.; Moayedi, H. Effects of Using Pozzolan and Portland Cement in the Treatment of Dispersive Clay. The Scientific World Journal 2013, 2013,1-10. [CrossRef] https://doi.org/10.1155/2013/547615.

7. Zeyad, A.M., Tayeh, B.A, Yusuf, M. Strength and transport characteristics of volcanic pumice powder based high strength concrete, Construction and Building Materials, 2019, 216, 314-324 [CrossRef] https://doi.org/10.1016/j.conbuildmat.2019.05.026.

8. Zeyad, A.M., Almalki, A. Role of particle size of natural pozzolanic materials of volcanic pumice: flow properties, strength, and permeability. Arabian Journal of Geosciences, 2021, 14, 107. [CrossRef] https://doi.org/10.1007/s12517-020-06443-y

9. Goodarzi, A.; Salimi, M. Stabilization Treatment of a Dispersive Clayey Soil Using Granulated Blast Furnace Slag and Basic Oxygen Furnace Slag. Applied Clay Science 2015, 108, 61-69. [CrossRef] https://doi.org/10.1016/j.clay.2015.02.024

10. Consoli, N.; Samaniego, R.; Marques, S.; Venson, G.; Pasche, E.; Velásquez, L. Single Model Establishing Strength of Dispersive Clay Treated with Distinct Binders. Canadian Geotechnical Journal 2016, 53, 2072-2079. [CrossRef] https://doi.org/10.1139/cgj-2015-0606

11. Zeyad, A.M., Johari, M.A.M., Tayeh, B.A. and Yusuf, M. Pozzolanic reactivity of ultrafine palm oil fuel ash waste on strength and durability performances of high strength concrete. Journal of Cleaner Production, 2017, 144, 511-522. [CrossRef] https://doi.org/10.1016/j.jclepro.2016.12.121

12. Pandey, A.; Rabbani, A. Soil Stabilization Using Cement. International Journal of Civil Engineering and Technology 2017, 8, 316-322. [PDF]

13. Phanikumar, B.; Ramanjaneya Raju, E. Compaction and Strength Characteristics of an Expansive Clay Stabilised with Lime Sludge and Cement. Soils and Foundations 2020. [CrossRef] https://doi.org/10.1016/j.sandf.2020.01.007

14. Fine Grade Fly 2020: https://www.boral.com.au/products/cementitious-materials/flyash/fine-grade-fly-ash (accessed on 01 March 2020).
15. Bullen, F.; Suciu, C. In National Local Government Engineering Conference, The National Academies of Sciences, Engineering, and Medicine: Hobart, Tasmania, Australia, 1991, 95-98.

16. Kodikara J.; Chakrabarti S. Microstructure and its Relationship to Some Material Properties of Cementitiously Stabilised Crushed Basaltic Rock. Road \& Transport Research: A Journal of Australian and New Zealand Research and Practice, 2007,16(2),3-18. [CrossRef] https://doi.org/10.1080/10298430500068654

17. Volker, D.; White, C. Using 'Insitu Foamed Bitumen' and 'Triple Blend' Additives to Rehabilitate Fatiguing Cement Treated Pavements in Fitzroy District. Engineering Technology ForumPractical Research into Action 2016, Queensland, Australia,4-63. [PDF]

18. Volker, D. (Department of Transport and Main Roads, Pinkenba, Queensland, Australia). Personal communication, 2020.

19. Rengasamy, P. and Walters, L. Introduction to Soil Sodicity. Technical Note, 1994

http://vro.agriculture.vic.gov.au/dpi/vro/vrosite.nsf/0d08cd6930912 d1e4a2567d2002579cb/813c7894348b29d4ca256ea8000327c6/\$FI LE/crc\%20intro\%20soil\%20sodicity.pdf (accessed 01 March 2020).

20. Li, Q.; Chen, J.; Shi, Q.; Zhao, S. Macroscopic and Microscopic Mechanisms of Cement-Stabilized Soft Clay Mixed with Seawater by Adding Ultrafine Silica Fume. Advances in Materials Science and Engineering 2014, 2014. [CrossRef] https://doi.org/10.1155/2014/810652

21. Demir, I.; Guzelkucuk, S.; Sevim, 3.; Filazi, A.; Goktug Sengul, C. Examination of Microstructure of Fly ash in Cement Mortar. International Journal of Advances in Mechanical and Civil Engineering 2018, 5, 49-51. [PDF]

22. Soil Sodicity | Victorian Resources Online | Agriculture Victoria 2020.

http://vro.agriculture.vic.gov.au/dpi/vro/vrosite.nsf/pages/soil soilsodicity (accessed 03 March 2020).

23. Methods of Testing Soils for Engineering Purposes-Method 3.9.1: Soil Classification Tests - Determination of the Cone Liquid Limit of a Soil; AS 1289.3.9.1; Standards Australia: Sydney, Australia, 2015.

24. Methods of Testing Soils for Engineering Purposes-Method 3.2.1: Soil Classification Tests - Determination of the Plastic Limit of a Soil- Standard Method; AS 1289.3.2.1; Standards Australia: Sydney, Australia, 2009.

25. Methods of Testing Soils for Engineering Purposes-Method 5.2.1: Soil Compaction and Density Tests - Determination of the Dry Density / Moisture Content Relation of a Soil Using Modified Compactive Effort; AS 1289.5.2.1; Standards Australia: Sydney, Australia, 2017.

26. Methods of Testing Soils for Engineering Purposes-Method 5.1.1: Soil Compaction and Density Tests - Determination of the Dry Density / Moisture Content Relation of a Soil Using Standard Compactive Effort; AS 1289.5.1.1; Standards Australia: Sydney, Australia, 2017.

27. Methods of Testing Soils for Engineering Purposes -Method 3.8.1: Soil Classification Tests - Dispersion - Determination of Emerson Class Number of a Soil; AS 1289.3.8.1; Standards Australia: Sydney, Australia, 2017. 
28. Methods of Testing Soils for Engineering Purposes - Method 3.8.3. Soil Classification Tests - Dispersion - Determination of Pinhole Dispersion Classification of a Soil; AS 1289.3.8.3; Standards Australia: Sydney, Australia, 2014.

29. Cao, H.; Bucea, L.; Ray, A.; Yozghatlian, S. The Effect of Cement Composition and $\mathrm{pH}$ of the Environment on Sulfate Resistance of Portland Cements and Blended Cements. Cement and Concrete Composites 1997, 19,161-171. [CrossRef] https://doi.org/10.1016/S0958-9465(97)00011-5

30. Bakharev, T.; Sanjayan, J.; Cheng, Y. Alkali Activation of Australian Slag Cements. Cement and Concrete Research 1999, 29,113-120. [CrossRef] https://doi.org/10.1016/S0008-8846(98)00170-7

31. Kampala, A.; Horpibulsuk, S. Engineering Properties of Silty Clay Stabilized with Calcium Carbide Residue. Journal of Materials in Civil Engineering 2013, 25 (5), 632-644. [CrossRef] https://doi.org/10.1061/(ASCE)MT.1943-5533.0000618

32. General

$$
\text { Purpose Cement }
$$
https://www.boral.com.au/products/cementitious-materials/cementbagged/general-purpose-cement (accessed 17 March 2020).

33. Sitarz, M.; Hager, I.; Choińska, M. Evolution of Mechanical Properties with Time of Fly-Ash-Based Geopolymer Mortars Under the Effect of Granulated Ground Blast Furnace Slag Addition. Energies 2020, 13, 1135. [CrossRef] https://doi.org/10.3390/en13051135

34. Methods of Testing Soils for Engineering Purposes-Method 3.6.1: Soil Classification Tests - Determination of the Particle Size Distribution - Standard Method of Analysis by Sieving; AS 1289.3.6.1; Standards Australia: Sydney, Australia, 2009.

35. Methods of Testing Soils for Engineering Purposes-Method 1.1: Sampling and Preparation of Soils - Preparation of Disturbed Soil Samples for Testing; AS 1289.1.1; Standards Australia: Sydney, Australia, 2001.

36. Benson, C.; Daniel, D. Influence of Clods on the Hydraulic Conductivity of Compacted Clay. Journal of Geotechnical Engineering 1990, 116, 1231-1248. [CrossRef] https://doi.org/10.1061/(ASCE)0733-9410(1990)116:8(1231)

37. Tinjum, J.; Benson, C.; Blotz, L. Soil-Water Characteristic Curves for Compacted Clays. Journal of Geotechnical and Geoenvironmental Engineering 1997, 123, 1060-1069. [CrossRef] https://doi.org/10.1061/(ASCE)1090-0241(1997)123:11(1060)

38. Methods of Testing Soils for Engineering Purposes-Method 2.1.1: Soil Moisture Content Tests - Determination of the Moisture
Content of a Soil - Oven Drying Method (Standard Method); AS 1289.2.1.1; Standards Australia: Sydney, Australia, 2005.

39. Methods for Preparation and Testing of Stabilized Materials -Method 4: Unconfined Compressive Strength of Compacted Materials; AS 5101.4; Standards Australia: Sydney, Australia, 2008.

40. Mohammed, A.N., Johari, M.A.M., Zeyad, A.M., Tayeh, B.A. and Yusuf, M.O. Improving the engineering and fluid transport properties of ultra-high strength concrete utilizing ultrafine palm oil fuel ash. Journal of Advanced Concrete Technology, 2014, 12(4), 127-137. [CrossRef] https://doi.org/10.3151/jact.12.127

41. Holt, C.; Freer Hewish, R.; Hewish, R. The Use of Lime-Treated British Clays in Pavement Construction. Part 1: The Effect of Mellowing on the Modification Process. Proceedings of the Institution of Civil Engineers - Transport 1998, 129, 228-239. [CrossRef] https://doi.org/10.1680/itran.1998.31194

42. Ali, H.; Mohamed, M. The Effects of Compaction Delay and Environmental Temperature on The Mechanical and Hydraulic Properties of Lime-Stabilized Extremely High Plastic Clays. Applied Clay Science 2017, 150, 333-341. [CrossRef] https://doi.org/10.1016/j.clay.2017.09.019

43. Moravej, S.; Habibagahi, G.; Nikooee, E.; Niazi, A. Stabilization of dispersive soils by means of Biological Calcite Precipitation. Geoderma 2018, 315, pp.130-137. [CrossRef] https://doi.org/10.1016/j.geoderma.2017.11.037

44. Little, D.; Herbert, B.; Kunagalli, S. Ettringite Formation in LimeTreated Soils. Transportation Research Record: Journal of the Transportation Research Board 2005, 1936, 51-59. [CrossRef] https://doi.org/10.1177/0361198105193600107

45. Harris, P.; Harvey, O.; Jackson, L.; DePugh, M.; Puppala, A. Killing the Ettringite Reaction in Sulfate-Bearing Soils. Transportation Research Record: Journal of the Transportation Research Board 2014, 2462, 109-116. [CrossRef] https://doi.org/10.3141/2462-13

46. C Sekhar, D.; Nayak, S. SEM And XRD Investigations on Lithomargic Clay Stabilized Using Granulated Blast Furnace Slag and Cement. International Journal of Geotechnical Engineering 2017, 13, 615-629. [CrossRef] https://doi.org/10.1080/19386362.2017.1380355 